\title{
Transportation Automation System Design for Visually and Hearing Impaired Users in the Digital Environment
}

\author{
Jongbin Lee ${ }^{1}$, Seong Ki Kim ${ }^{2}$ \\ ${ }^{1}$ Professor, Division of SW Convergence, Sangmyung University, Republic of Korea, \\ Belle.lee@smu.ac.kr \\ ${ }^{2}$ Assistant Professor, Division of SW Convergence, Sangmyung University, Republic of Korea, \\ skkim9226@smu.ac.kr \\ Corresponding author: Seong Ki Kim
}

\begin{abstract}
The transportation card ticket vending machine, a kiosk system first introduced in Korea in 1997, became a world-top-tier technological innovation and was gradually implemented in many other countries. Today, it is practically everywhere and expanded to other variable industry such as restaurant, concert hall and movie theater, and so on, because of cheaper of labor costs and convenience. It has recently achieved more than $95 \%$ installed vendinFg machine in most of service markets, stores, even local supermarkets. However, this being part of the digital age, causes a digital discrimination especially on the persons with visual or hearing impairment, which makes performing everyday activities difficult if not properly addressed. Thus, the study proposed an improved transportation card vending machine system, with design and operational flow that will serve these persons with disabilities. It has a simplified menu display with voice recognition and body language service, and a service mode setting automatically detecting the disability level of the user. To increase the success rate among kiosk users, the system recommends destinations through voice or text interface to lead the users to choose only one digit number representing their exact destination. It is intended to reduce the fail attempt during user interaction and to provide an improved transportation card vending machine system with design and operation flow that will serve these persons with disabilities.
\end{abstract}

Keywords: Auto Machine, Kiosk Design, Voice Recognition, Hearing Impaired, Transportation Ticket Vending Machine, Visually Impaired

\section{Introduction}

Today, unmanned vending machine is exponentially expanding because labor burden is highly increasing due to higher base wages. An unmanned vending machine relies on user interaction with the system interface, which includes accessing various buttons or through a touch screen[1][2]. It uses visual application with advanced multimedia devices such sound, graphics, and communication cards among other peripherals. based on users' satisfaction from various service benefits[3][4], it had been regarded as a system standard, and is spreading its functions through machines assisting our daily activities, the government agencies, our local communities[5], self-banking, ticket sales, public hall information centers, and the education services in schools[6].

According to Shahan investment and market analysis of securities vending machine, they have been growing up more than four times from 60 billion won in 2006 to 250 billion won in 2017, and the the

Received: February 09, 2021; $1^{\text {st }}$ Review Result: March 26, 2021; $2^{\text {nd }}$ Review Result: May 17, 2021

Accepted: June 30, 2021 
market of the global interactive unmanned vending machine is forecast to grow by an average of $6 \%$ per year until 2023[7].

Despite the diversified services and rapidly increasing uses of unmanned vending machines, in reality, these technology causes difficulties on access among persons with disabilities, especially the visually and hearing impaired. They are eventually isolated in the actual use of the system[8].

In this study, a modified system design of the unmanned vending machine by simplifying and recomposing the operating flow for visually/hearing impaired users is proposed. In addition, the proposed system includes a service that detects the registered disability of the user through RFID scanning of the users' smart total welfare card to identify the exact service needed

\section{Contents}

\subsection{Automatic System Mode Setting Design}

Most of the unmanned vending machines installed around us are for physically-abled non-disable users. Some of the machines have braille in small size found on the bottom of the devices for hearing impaired users, which is almost impossible to recognize the functions of the device and how to get started. From a survey on the use of vending machine for disabled users, the machines are not designed to consider the disabled users' step-by-step access. If the service is somehow available, the disabled users faced difficulties understanding the functions and explanations, and thus, give up using the system in the end.
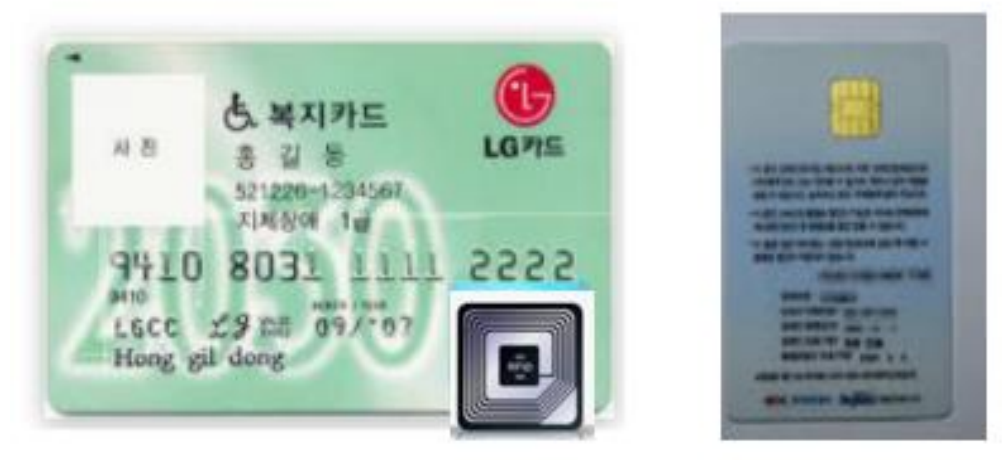

[Fig. 1] Smart total Welfare Card

The proposed method is to configure the disability level service automatically on the machine through the information connected to the RFID tag on the Smart total welfare card of the user. It can send/receive data accurately within one-to two-meter boundary likely machine boots[9][10]. with this approach, machine can set service mode as needful service without additional efforts for disabled users. All the smart total welfare cards need to associated with the unique RFID tags of the users and all machines should have an RFID reader to exchange data between in accessible boundary. Most of the machines have it and some of the welfare cards RFID now. Therefore, the rest of the IDs should be upgraded with the chip in a non-costly manner. [Fig. 1] shows where or how it can be integrated on the ID. Once the user gets near the machine, it will detect the disability based on the RFID. The machine then enables the signal language mode along with letter menu for the deaf and voice mode with microphone/speaker enabled for the visually impaired. [Fig. 2] shows how to configure the 
proposed design for the said persons with disabilities. It improves the service mode setting approach from conventional to a more satisfying service for the disabled users beyond advanced technology.

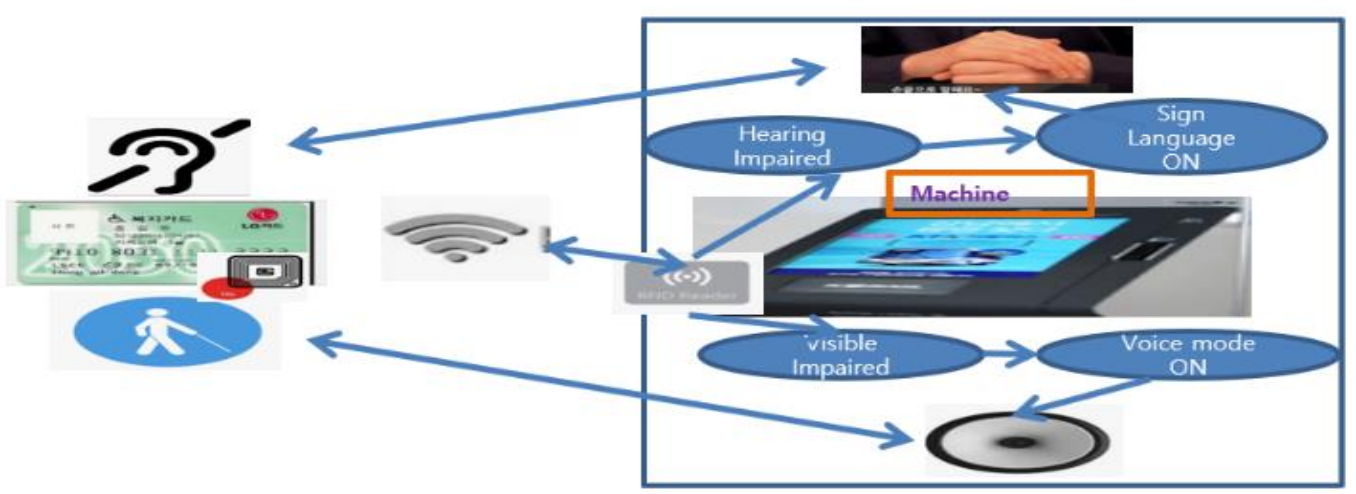

[Fig. 2] Proposed System Design

\subsection{System Operating Flow for Customized Services}

[Fig. 3] shows the traditional machine menu configuration of a transportation system[11]. As shown, the menu has many options and might be complex for users to access various services[12]. These complex options would have another hurdle to disabled users in understanding and accessing the machine. So, as a first step, this study proposed to reconfigure and simplify the menu to avoid confusion and operation error and time. Because their recognition ability is not similar with the normal users, most of the machine interface does not suit them. This paper designed the key functions highlighted and contained on one page, thus, requiring minimum interaction.

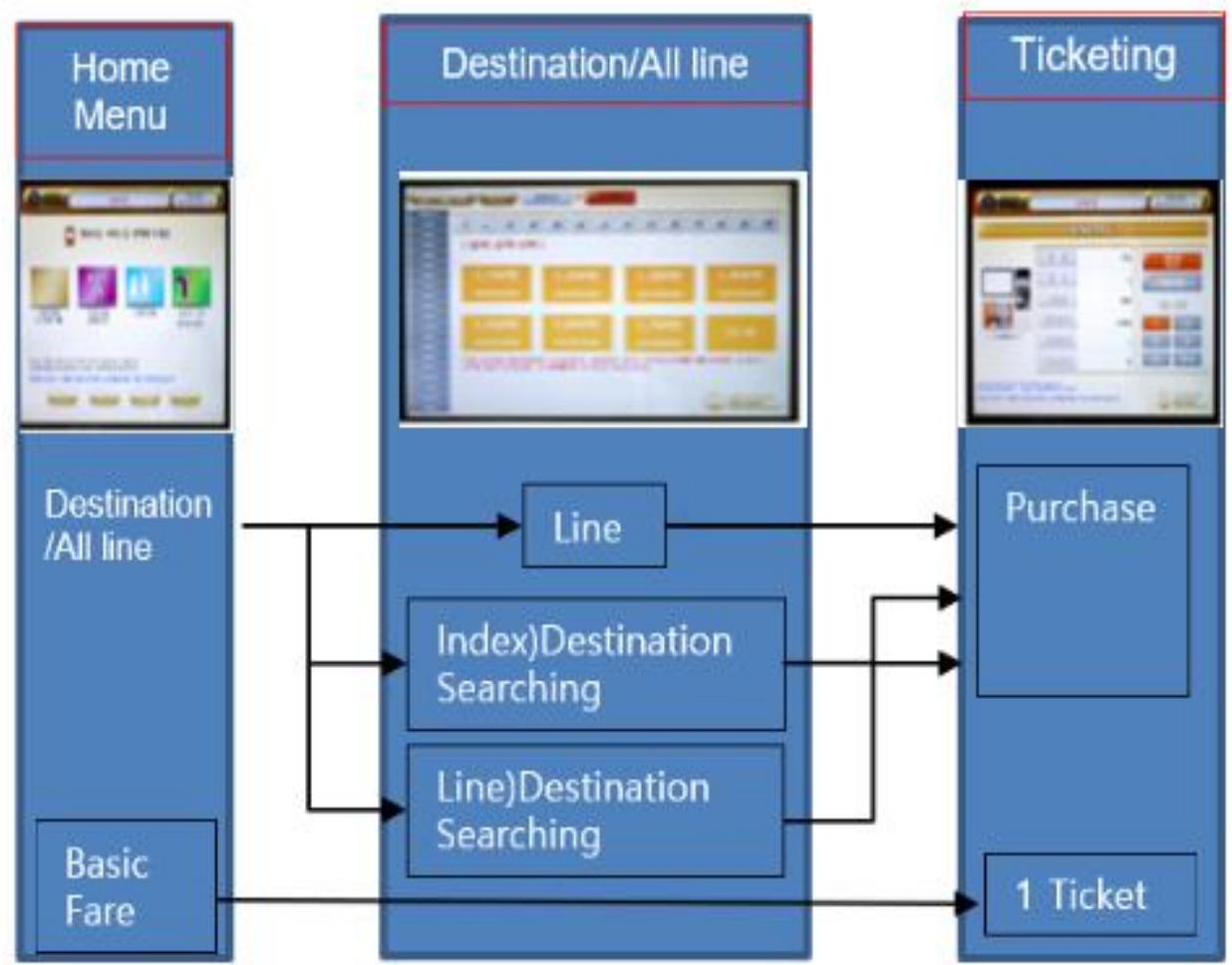

[Fig. 3] Original Menu of Transportation Ticket Machine 
[Fig. 4] shows the simplified menu, which only asks for the destination. It also suggests matched words from each letter encoded by the user in the destination box. The suggestions become more specific as more letters are being typed. In the "Choose Destination "page, a magnifying glass symbol for the non-visually impaired and a sign language symbol for the deaf is visible.

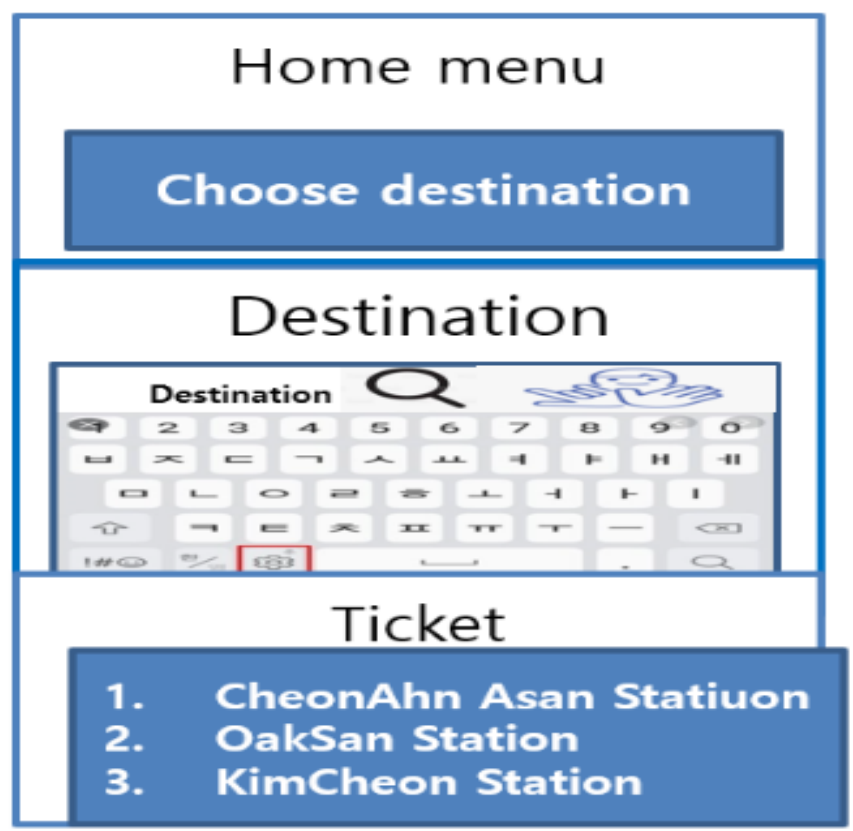

[Fig. 4] Simplified Menu of the Transportation System

\subsubsection{Automatic Voice Service for Visually Impaired Users.}

The system recognizes the disability level of the user from welfare card via the RFID tag and sets the service mode required for the user. For visually impaired users, the system enables a voice mode and start a voice service.

First, it will ask the transportation line destination among the three lines such as Gyongbu-line, Honam-line and others, with corresponding digit number. For instance, No. 1, 2, and 3 represents the Gyongbu-line, Honam-line, and others, respectively. Then, the machine will wait for the user's response. Second, it will ask name of destination and searches the database. These steps reduce the searching time than full searching time by $30 \%$. This also reduces the interaction error caused by user.

In the paper, the system can create useful candidate list by applying Selection Algorithm of Candidate Destination which recommends a set of stations based on encoded letters. It can help user to find and choose their destination accurately and quickly without operation error. It means they can smoothly move to second step without trouble. This method is introduced to make it easier to use by reducing mental fatigue caused by the system complexity to the disabled users. In addition, could have weak speech and physical condition than others. Thus, in the system, we have to consider their convinces. So, we applied list creation method with priority rank to recommend more optimal candidate list based on first letter importance rule and feel them more comfortable under unstable outside condition by optimal list providing as much as they can. The system enables the voice mode and asks the destination line using digits 1,2, and 3. Each number corresponds to Gyongbu Line, Honam Line and other Line, then moves to the next step. Then the systems asks the user to state the destination station. For example, when the user speaks "Dae Jong", the system presents all stations with "Dae" and "Jong" with 
corresponding station number such as "1. Dae Gu”, "2. Dong Dae Goo", "3. DaeJoen”, "4. SeDaeJoen”, and "5. Others". Then it will wait for the user to state the station number. If the choice is between 1-4, it moves to the third step and informs the user of the total cost of the ticket, then process the payment via the smart total welfare card. If the user chose 5, it goes back to the first step, asks the destination line, and repeats the rest of the process.

Each number corresponds to Gyongbu Line, Honam Line and other Line and move to next step. Here it requests to speak destination and creates candidate list with similar station name to contain each spoken letter and sort them with letter priority and then finally shows final list decided on the screen by sorting them with first letter importance rule for final list. For example, when user speak out destination with "DaeJong station" and system might recognize the letter of "DaeJong", it create candidate list to contain "Dae" "Jong" to introduce the method of Selection Algorithm of Candidate Destination first and then apply priority sorting rule on the list. Finally, it speaks created list with 1. Dae Gu, 2. Dong Dae Goo, 3. Daejeon, 4. SeDaeJoen and 5. Others and wait for user choice. If it is chosen from 1-4, it moved to 3rd step to inform user of total cost and ask whether to get the ticket. If user select ticketing finally, it starts payment process via smart welfare card. If user choose 5 . Others, it goes back to 1st step to ask line of destination and then follow them again.

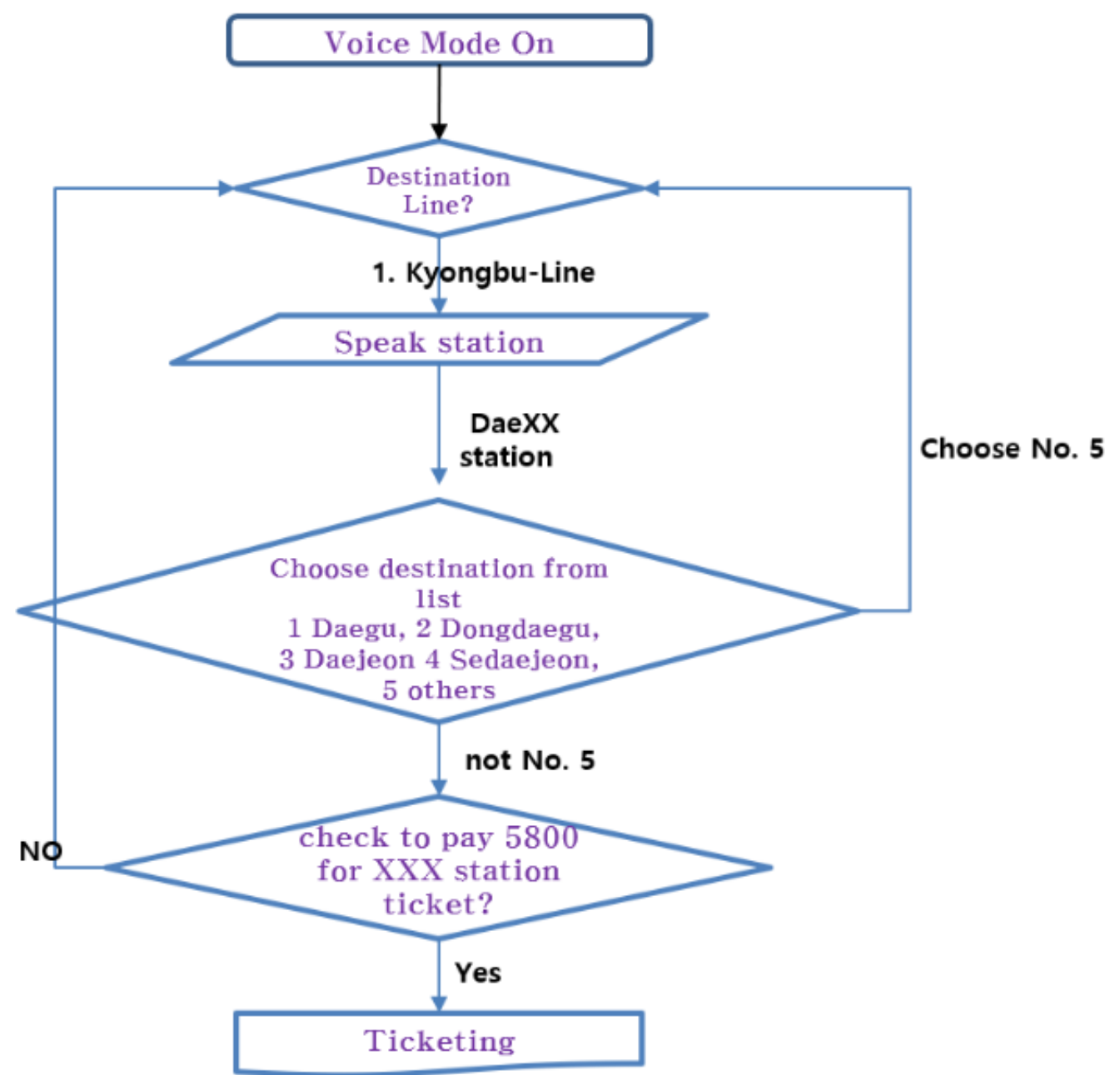

[Fig. 5] Proposed Transportation Vending Machine with Voice Service for Visually Impaired Users 


\subsubsection{Selection Algorithm of Candidate Destination}

In the paper, the list creation method of Selection Algorithm of Candidate Destination is proposed. It is applied when it does not find matched destination based on the voice data of the user. The algorithm makes array that contains all the letters corresponding to Korean Complete code range at server, where all of full name are assigned to index numbers. It gets the index of full station names in array when received letter matched one in array corresponding complete name. For example, "Choan" and "Ahn" are recognized by voice. All stations with "Choan" and "Ahn" will be presented.

The server contains all the station names with number and the index of each station corresponding to each letter in a table format as shown in [Fig. 6]. This is sent to the client via spring boot[13] after converting to JASON format[14]. Finally, the client presents the result as ("word":"Choan", "count":3, "list": " $2 / 4 / 5$ "). This means that the number of times with letter "Chon" represents 3 at station index with 2, 4 and 5. The client save the table parsed.

The summary of this process is as follows. The server takes the text file of the station, delivers it to the client in JSON format, and processes the indexing process to create a list of recommended stations through similar search. In the case of indexing in the machine client, it is necessary to have all the Korean encoding arrays, so it relies on processing in a resource-rich server, and only the indexing results delivered from the server are processed in client. It helps space burden of client reduced. If Choan letter is received, it is sent to server to find the letter of Choan from index database with all stations. The client of system is parsing and getting only indexing result from server, so system load could be reduced.
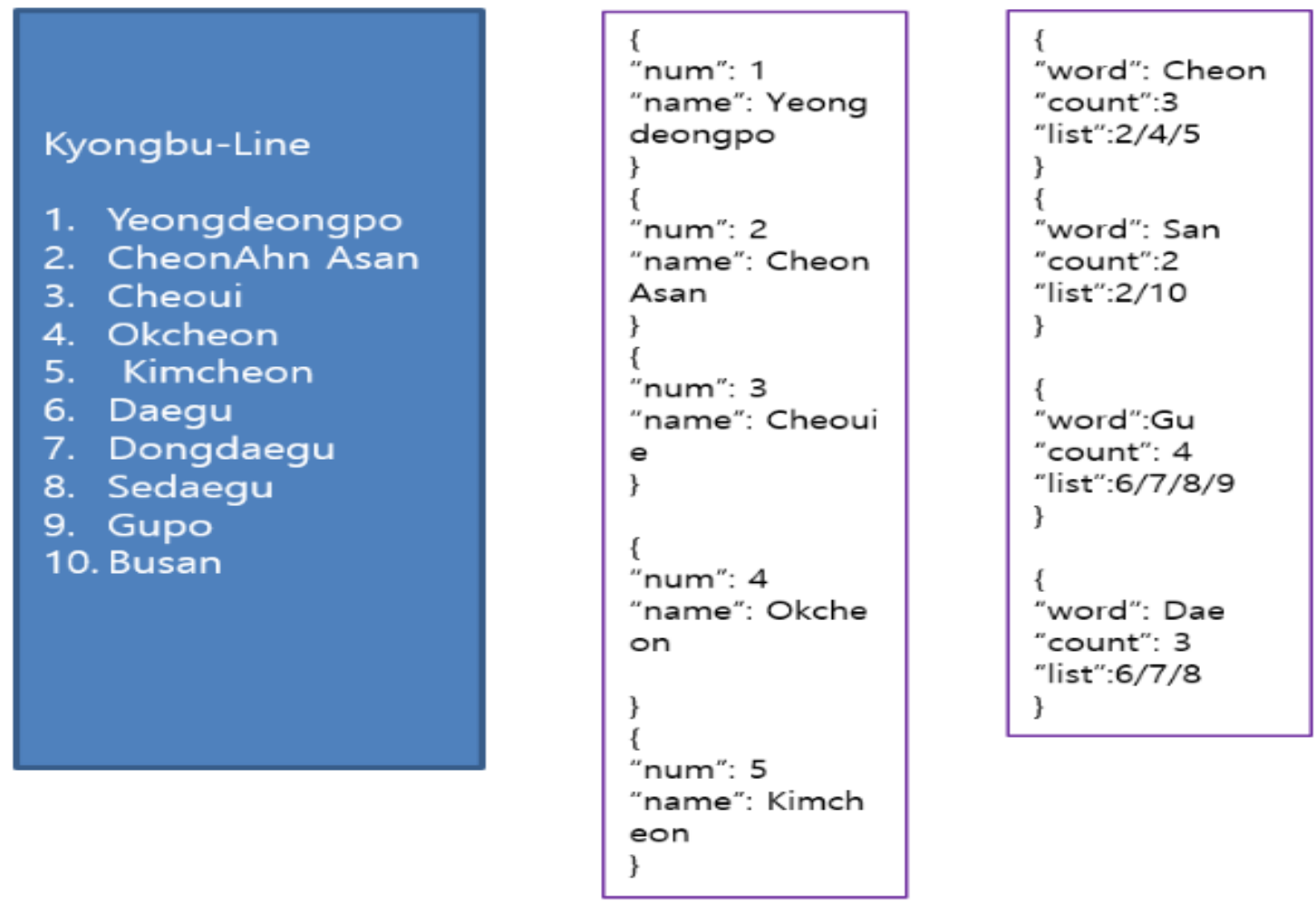

[Fig. 6] The Menu saved as a Text File on the Server and the Result Converted form the JASON Format

When table is generated to create a candidate, system generally use ascending or descending sorting algorithm without considering the feature of system service. However, we consider it to provide 
more user convenience and proposed priority sorting rule with first letter weight, and apply to recompose the 1 st list and then decide the final candidate list.

\subsubsection{Priority Sorting with First Letter Weight}

For disabled users, it might be difficulty to choose a number even if there are many choices proposed due to weak concentration in making a decision. In order to get rid of their physical and mental fatigue in the outside environment, the paper tried to propose an optimal candidate list for selection. The researchers propose to recompose list based on priority sorting with first letter importance rule based on created candidate lists and they can find out their destination quickly from the number list. This method is to give more weight to first voice letter and assign them to front number among candidates for quick check without back number check if their index count is same. [Fig. 7] shows the overall system operation flow at server and client side.

\section{Server}

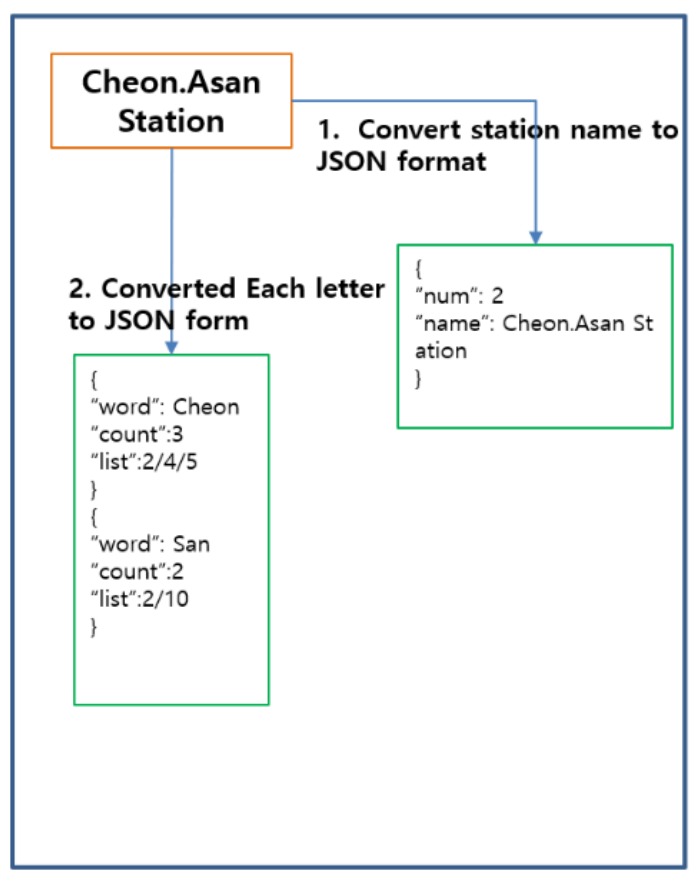

Andriod

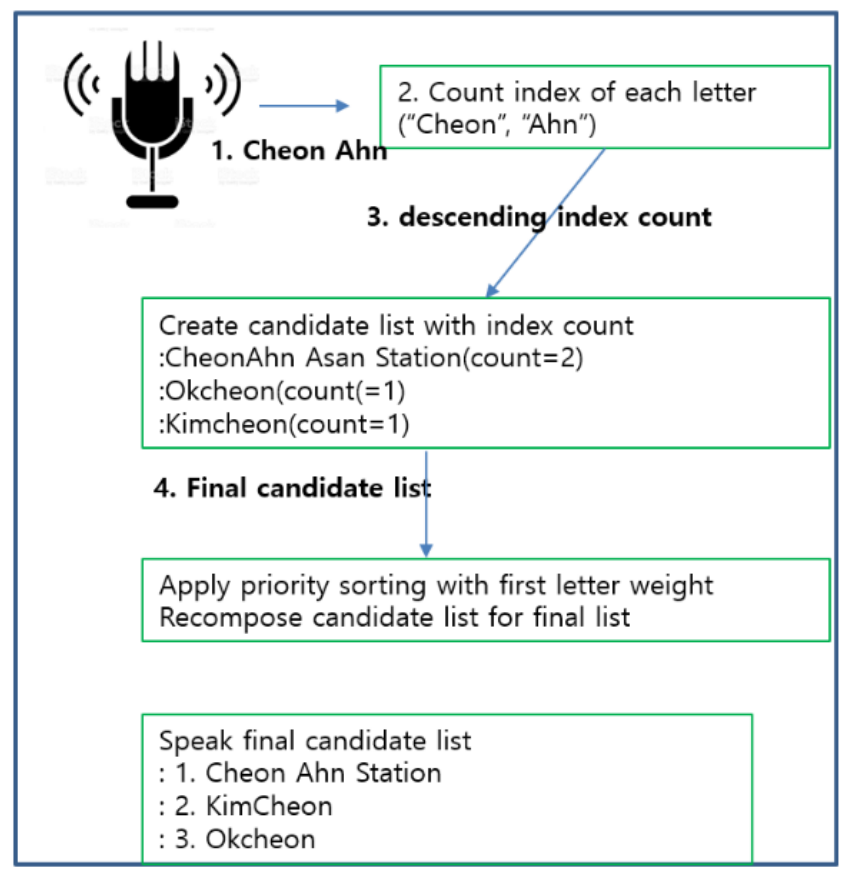

[Fig. 7] Proposed System Flow on Server and Client Side for Voice Service

As shown in [Fig. 7], the server has a station number as flow 1 and index list of each station name corresponding to each letter among full name and count them as flow 2 at server. The client received only the 2nd flow in JASON format and then create the candidate list based on the index count, then recompose it with the first letter importance rule and finally show the candidate that the first letter matched among the list to the front side.

\subsubsection{Sign Language Mode Enable for Hearing Impaired}

The proposed sign language mode is set automatically when the machine recognized the hearing impairment level of the disabled user through the RFID tag in the smart welfare card. The designed inquiry display of destination was simplified with simple type form, large font size, and sign language screen because those users with hearing problem also have weak vision. [Fig. 8] shows the destination inquiry screen for deaf users. 


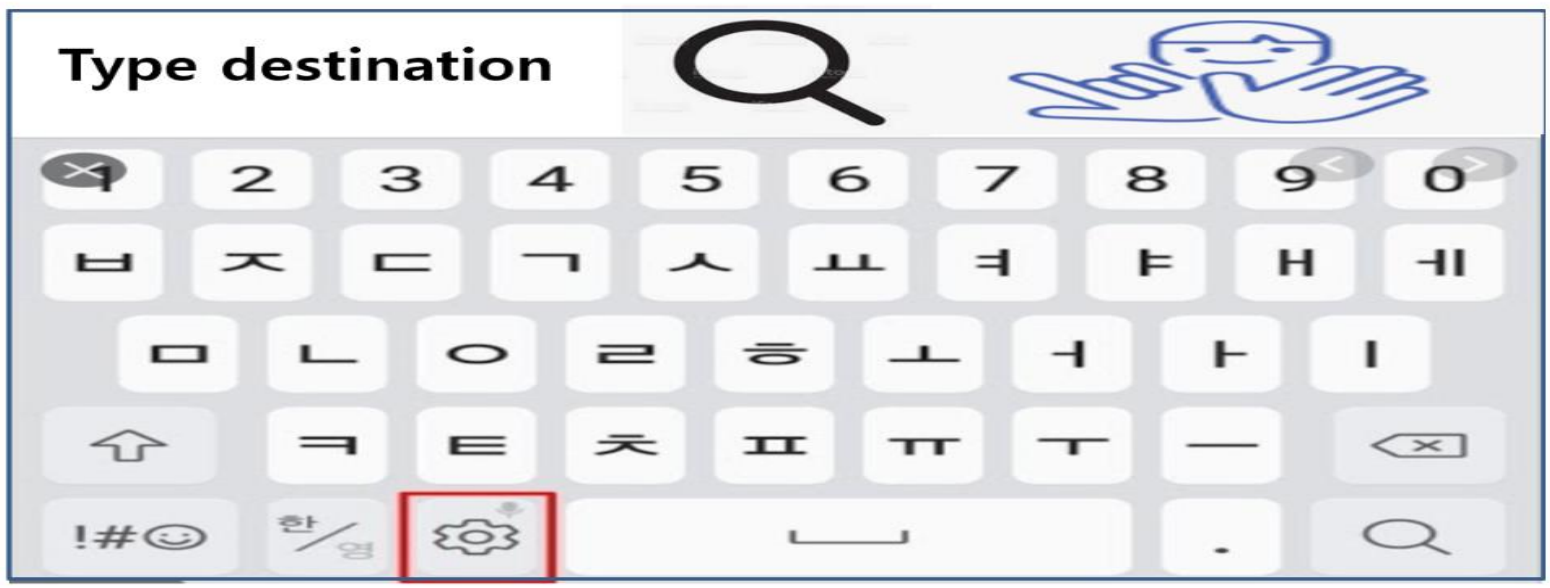

[Fig. 8] Menu Design for Hearing Impaired User

As shown in [Fig 8], the sign language symbol next to the magnifying glass icon explains how to use the menu on the screen. The magnifying glass enlarges the character or word typed. When the typed character matched the name of the station, it issues the ticket and credits the payment to the smart welfare card of the user. If there is no matched station, the system shows a candidate list using the Selection Algorithm of Candidate Destination based on index and index count and priority sorting based on first letter importance rule. Users can press the digit from the list on the screen along with the sign language. [Fig. 9] explains the overall system working flow from system setting to ticket issuance.

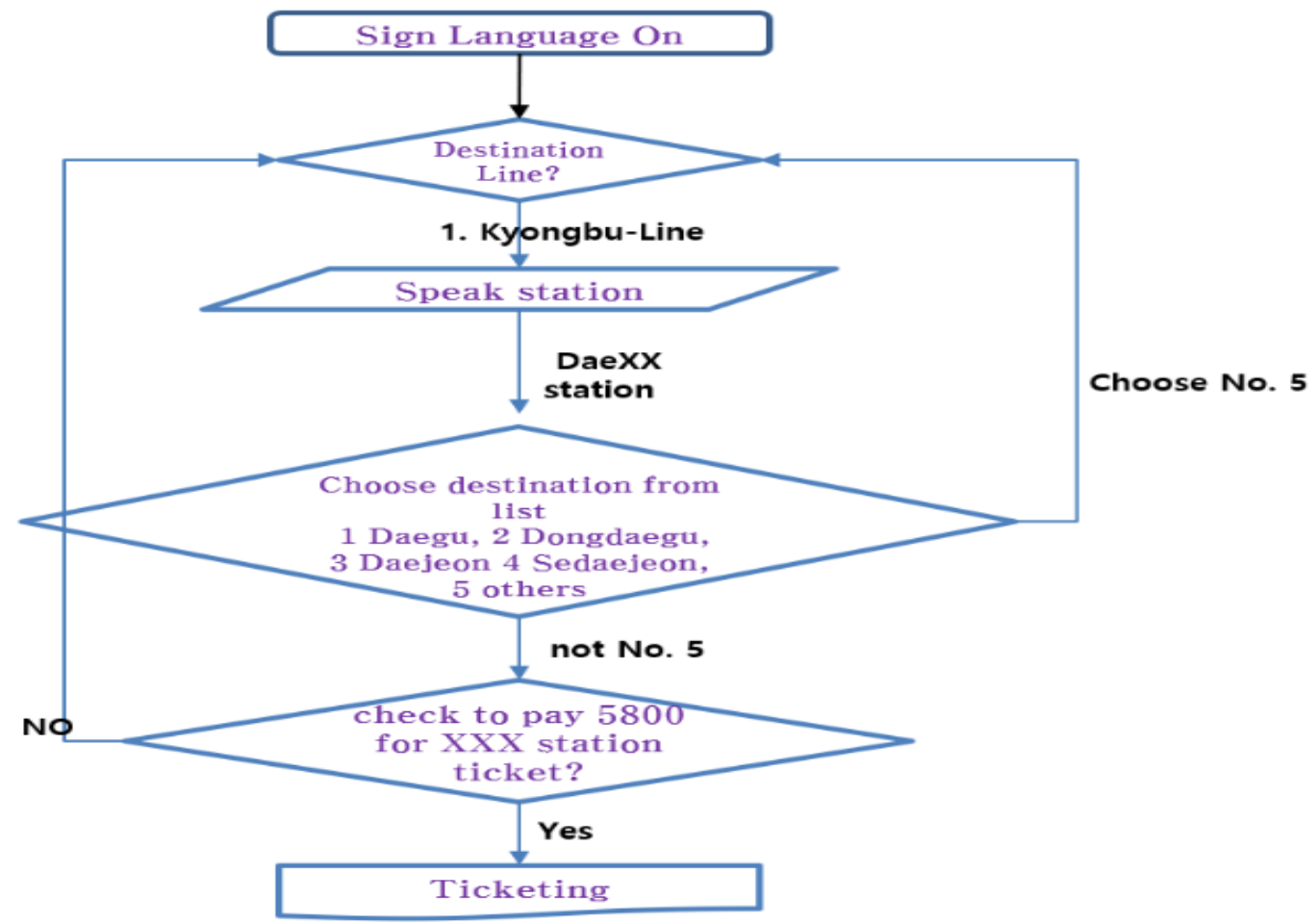

[Fig. 9] Menu Operation Flow for Hearing Impaired User 


\section{Conclusions}

Developing software technology around us benefits our daily life conveniently in various ways. However, there are many digital disadvantaged users around us such as the elderlies, the disabled persons, and so on. Among the disabled users are the visually and hearing impaired. Thus, the paper proposed an automation system design for the transportation ticket, which will improve the system flow and system experience for the said users.

In this paper, researchers simplified the automation menu structure for various users. It contains upgraded services to support body language or voice service by automatically changing the system service mode based on the recognized disability in the RFID tag. It helps to increase the success rate and user satisfaction upon completing a system transaction. This will also enable the said users to appreciate advanced technology with services customized to their needs. The proposed system has an improved operation flow to provide optimized candidate destination list based on each station's index containing all station names and index count corresponding the typed letter/stated word/s of the user. It reduces the failures caused by human error. The proposed system design for disabled users will be applied to other systems supporting their daily activities[15][16]. The result of the study is intended to help the digital disadvantaged users to enjoy a more convenient life from advanced technology.

\section{References}

[1] H. H. Kim, D. S. Shin, Development of integrated operating system for transportation card unmanned sales charging machines, Journal of the Korea society of computer and information, (2010), Vol.15, No.3, pp.99-109, DOI: 10.9708/jksci.2010.15.3.099

[2] S. Hagen, F. Sandnes, Toward accessible self-service kiosks through untelligent user interfaces, Personal and Ubizuitous Computing, (2010), Vol.14, No.8, pp.715-721, DOI:10.1007/s00779-010-0286-8

[3] Infrastructure and Transport, ITS Glossary 2010, ITS Korea, Ministry of Land, (2010)

[4] F. Sandnes, H. Jian, Y. Huang, User Interface Design for Publi Kiosks: An Evaluation of the Taiwan High Speed Rail Ticket Vending Machine, Journal of Information Science and Engineering, (2010), Vol.26, No.1, pp.307-321.

[5] J. Paradi, A. Ghazarian-Rock, A framework to evaluate video banking kiosks, Omega, (1998), Vol.26, No.4, pp.523539.

[6] M. Johmston, S. Bangalore, MATCHK iosk: A Multimodal Interactive City Guide, The 40th annual meeting and conference of association for computational Linguistics, (2004), September 11-14, Taiwan

[7] Daily Shinhan Think, Shinhan Investment Research Center, (2018), Vol.3342.

[8] W. Kim, I. Kwon, H. Jo, H, Park, Snort Rule Optimizer: Developing a tool to efficiently optimize Snort Rules with LCS Algorithm, Korean Information Science Association 2013 Korea Computer Science Conference Paper Collection, Korean Institute of Information Scientists and Engineers, pp.756-758, July 15-18, (2013), Jeju, Korea

[9] Alex Polacco, Kayla Backes, The Amazon Go Concept: Implications applications and sustainability, Journal of Business and Management, (2017), Vol.24, No.1, pp.79-92, DOI: 10.6347/JBM.201803_24(1).0004

[10] Alan Boyle, Ready to be tracked at the grocery store? Amazon's mini-mart raises new questions for digital privacy, Geek Wire, December 7, (2016)

[11] Shin-Hye Hwang, Jong-Hoon Choe, A study on User Experience of Automatic Ticket Vending Machine UI :Focused on Seoul Metro Line 9, Journal of the Korea contents association, (2015), Vol.15, No.6, pp.54-61, DOI: https://doi.org/10.5392/JKCA.2015.15.06.054 
[12] S. W. Kim, M. S. Min, S. M. Ph, The development trend of transportation information system through transportation card data, The 25th Conference of the Korean Society for railway, (2011), May 10-13; Busan, Korea

[13] https://spring.io/projects/spring-boot, Feb 09 (2021)

[14] https://www.json.org/json-ko.html, Feb 09 (2021)

[15] Pedram Gharani, Hassan A, Karimi, Context-aware obstacle detection for navigation by visually impaired, Image and Vision Computing, (2017), Vol.64. pp.103-115, DOI:10.1016/j.imavis.2017.06.002

[16] Dong Ueong Jeong, Jiyoung Kwahk, Sung H. Han, Joohwan Park, Mingyu Lee, Hyeji Jang, A pedestrian experience framework to help identify impediments to walking by mobility-challenged pedestrians, Journal of Transport \& Health, (2018), Vol.10, pp.334-349, DOI: https://doi.org/10.1016/j.jth.2018.06.001 